\title{
Numerical simulation of rainfall with assimilation of conventional and GPS observations over north of Iran
}

\author{
Mohammad Ali Sharifi ${ }^{1}$, Majid Azadi ${ }^{2}$, Ali Sam Khaniani ${ }^{1, \star}$ \\ ${ }^{1}$ School of Surveying and Geospatial Engineering, University College of Engineering, University of Tehran, Tehran, Iran \\ ${ }^{2}$ Atmospheric Science and Meteorological Research Center, Tehran, Iran
}

\author{
Article history \\ Received November 14, 2015; accepted May 12, 2016. \\ Subject classification: \\ 3DVAR assimilation, WRF, GPS PWV, Surface observations, Rainfall.
}

\begin{abstract}
In this work, the effect of assimilation of synoptic, radiosonde and ground-based GPS precipitable water vapor (PWV) data has been investigated on the short-term prediction of precipitation, vertical relative $h u$ midity and PWV fields over north of Iran. We selected two rainfall events (i.e. February 1, 2014, and September 17, 2014) caused by synoptic systems affecting the southern coasts of the Caspian Sea. These systems are often associated with a shallow and cold high pressure located over Russia that extends towards the southern Caspian Sea. The three dimensional variational (3DVAR) data assimilation system of the weather research and forecasting (WRF) model is used in two rainfall cases. In each case, three numerical experiments, namely CTRL, CONVDA and GPSCONVDA, are performed. The CTRL experiment uses the global analysis as the initial and boundary conditions of the model. In the second experiment, surface and radiosonde observations are inserted into the model. Finally, the GPSCONVDA experiment uses the GPS PWV data in the assimilation process in addition to the conventional observations. It is found that in CONVDA experiment, the mean absolute error (MAE) of the accumulated precipitation is reduced about 5 and 13 percent in $24 \mathrm{~h}$ model simulation of February and September cases, respectively, when compared to CTRL. Also, the results in both cases suggest that the assimilation of GPS data has the greatest impact on model PWV simulations, with maximum root mean squares error (RMSE) reduction of $0.7 \mathrm{~mm}$. In the GPSCONVDA experiment, comparison of the vertical profiles of $12 \mathrm{~h}$ simulated relative humidity with the corresponding radiosonde observations shows a slight improvement in the lower levels.
\end{abstract}

\section{Introduction}

The ground-based global positioning system (GPS) is used as a new technique of remote sensing of the atmospheric water vapor since more than two decades. The GPS signals passing through the atmosphere encounter delay due to the atmospheric contents especially water vapor. The total delay is divided into two parts: wet and dry. Using surface temperature and pressure measurements the wet delay is mapped into the precipitable water vapor (PWV) [Bevis et al. 1992, Rocken et al. 1993].

Sub hourly measurements of the GPS PWV are accurate for values of less than $2 \mathrm{~mm}$ [Duan et al. 1996, Rocken et al. 1997]. The ground-based GPS observations compared with conventional methods of measuring water vapor in the atmosphere such as radiosonde observations, have a high temporal resolution, long-term stability and are independent of all-weather condition [Rocken et al. 1997, Yunck et al. 2000].

The formation of clouds and precipitations are directly related to the distribution of the atmospheric water vapor. Therefore, high-resolution measurements of this quantity can play an important role in numerical weather prediction (NWP) models [Mazany et al. 2002, Zhang et al. 2007].

Accurate initial conditions are necessary to have a better numerical prediction of the atmosphere. Assimilation of conventional (such as synoptic and radiosonde) and non-conventional (such as satellite and groundbased GPS) data can improve the initial conditions [Govindankutty and Chandrasekar 2011, Srinivas et al. 2012]. The variational data assimilation methods have the ability of direct assimilation of the observed variables such as satellite radiance, radar reflectivity and GPS PWV that are different from the model prognostic variables. Using this type of data assimilation approaches, several studies showed a positive impact in the simulation of the rainfall events [Lipton et al. 1995, Kalnay 2003, Zapotocny et al. 2007].

Many attempts have been made to evaluate the impact of the GPS water vapor observations assimilation on the NWP model outputs [Kuo et al. 1993, Kuo et al. 1996, Falvey and Beavan 2002, Zhang et al. 2007, Zhang et al. 2008, Bauer et al. 2011, Leiming et al. 2012].

Kuo et al. [1993, 1996] showed that the assimila- 
tion of PWV measurements into a NWP model improve the vertical structure of the predicted moisture field. Falvey and Beavan [2002] examined the potential of GPS PWV in the advanced regional prediction system (ARPS) model retrievals of precipitation. Based on their results, assimilation of hourly GPS PWV improved the predicted total precipitation of the model up to 3 percent. Also, the use of GPS PWV data assimilation can eliminate the wrongly predicted rainfall systems and increase the quality of rainfall events predictions in timing, location and intensity [Zhang et al. 2007, Zhang et al. 2008].

In a study, Leiming et al. [2012] assimilated the GPS PWV measurements together with the automatic weather station (AWS) observations into a short-range numerical model system using 3-dimensional variational (3DVAR) data assimilation scheme. They found that the data assimilation of these observations can improve the rainfall and temperature predictions. The Iranian permanent GPS network (IPGN) has been established to study the crustal deformation and also for navigation and surveying purposes. At present, this network consists of about more than 90 active stations which are mostly distributed in the northern part of Iran. So far, no effort has been made in using the observations of IPGN stations to improve the performance of NWP models. The main objective of this study is to present preliminary the results on the impact of 3DVAR assimilation of GPS PWV measurements together with the conventional synoptic and radiosonde observations in the simulation of rainfall over the northern part of Iran using the weather research and forecasting (WRF) model.

In Section 2, a brief description of conventional data, GPS PWV measurements and their estimation process are provided. The description of the numerical experiments, the WRF model settings used in this work and 3DVAR assimilation methodology are presented in Section 3. The result of the three data assimilation experiments (with different selection of observations) in the prediction of rainfall and moisture fields are compared in Section 4. The summary and conclusions are given in the last section.

\section{Data and case studies}

\subsection{Conventional data}

Most of the heavy precipitations with more than $100 \mathrm{~mm} /$ day, occurred in the southern coasts of Caspian Sea are associated with a thermal shallow and cold high pressure system located over Russia and the northern Caspian Sea. Due to the temperature difference between the warm water of Caspian Sea and relatively cold air in the shallow high pressure, intense evaporation occurs and thus air becomes saturated in the boundary layer. The low pressure aloft causes vertical motions and precipitations take place in the southern Caspian Sea. Accurate predictions of precipitations associated with the above mentioned mechanism is a challenging task and has much importance in operational forecasting. Thus in this research, two of such synoptic systems are selected to investigate the impact of the assimilation of radiosonde and synoptic station observations as conventional data and GPS water vapor measurements in numerical prediction of two rainfall cases (February 1, 2014, and September 17, 2014) over the northern part of Iran. The study area (inner domain of simulation) is located between geodetic latitudes of 33.06 to 39.44 and longitude 42.63 to 61.82 degrees.

Conventional observations of temperature, pressure, humidity and wind for 50 synoptic stations in the inner domain and 150 stations in the outer domain considered were used in the assimilation process. Figure 1 shows the spread of the Zagros and Alborz mountain ranges over the western and northern parts of Iran, respectively. Distribution of the synoptic stations over the country is more or less uniform. Three hourly synoptic data collected at surface stations along with the vertical temperature and humidity profiles observed at four radiosonde stations (yellow stars in Figure 1) were obtained from the I. R. of Iran Meteorological Organization (IRIMO) network. The radiosondes are lunched twice a day at 00 and 12 UTC. Total daily precipitation observations from rain gauges in the study area were used to validate the NWP model simulation of precipitation.

\subsection{GPS PWV data}

The GPS PWV values derived from the processing of the ground-based observations of the IPGN network with sub hourly temporal resolution are used to improve the numerical simulation of rainfall. The inner domain of the model is located in the northern part of Iran, mainly because heavy convective rainfall events occur in the northern part of Iran along the coast of Caspian Sea and in many cases NWP models fail to accurately forecast the precipitation over this region. Moreover, most of the ground-based GPS stations are located in the north and north-west parts of the country that lie inside our inner domain. Accurate precipitation forecast over north of Iran is thus a challenging task for professional forecasters. Distribution of GPS stations in the IPGN network over Iran topographic map along with the boundaries of the inner domain in the simulation is depicted in Figure 1.

The total atmospheric delay in the zenith direction and the components of position are estimated for each 


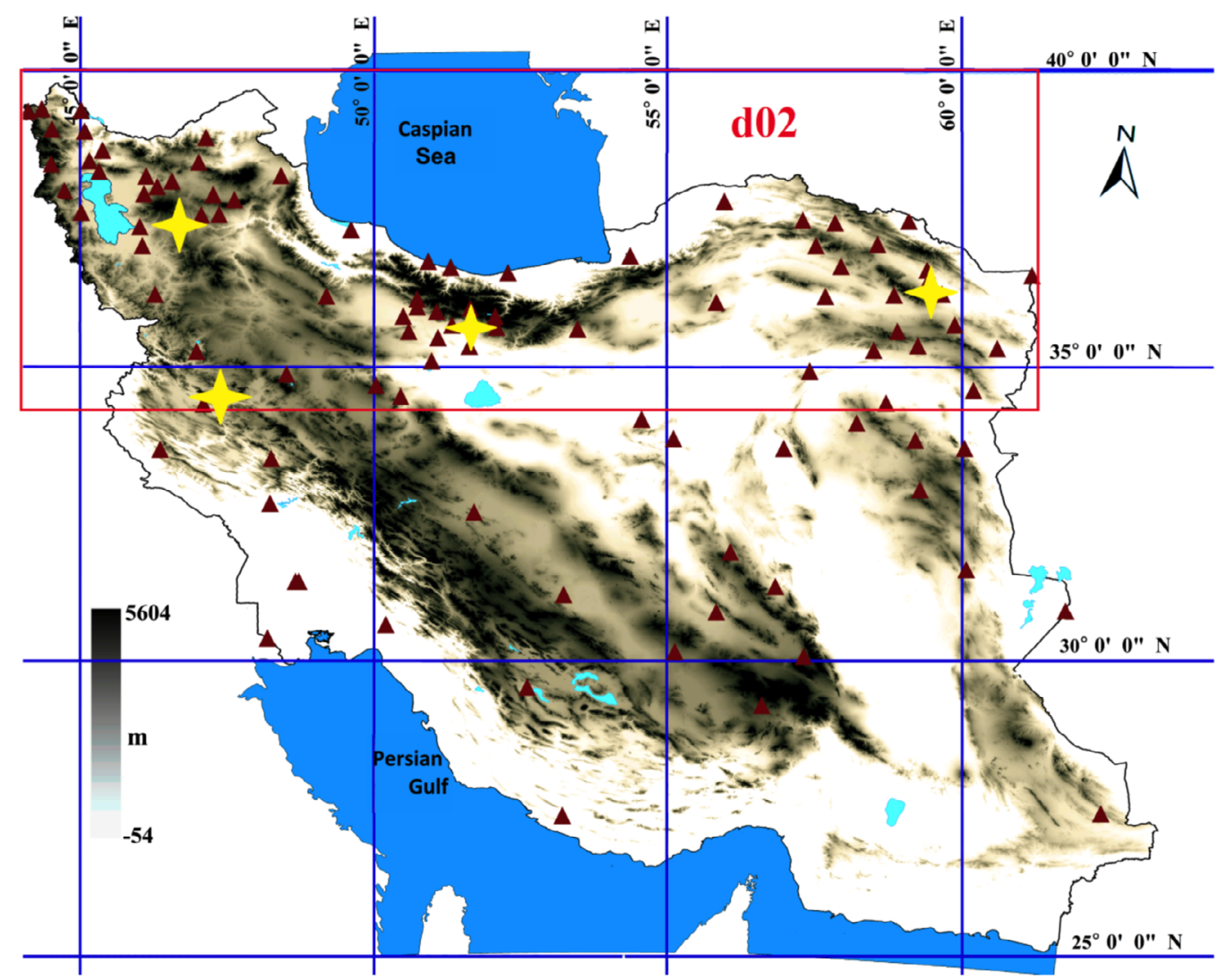

Figure 1. Distribution of IPGN stations together with topographic information over Iran. The red rectangle shows the inner domain of model. The yellow stars show the location of radiosondes in the domain.

station. Total tropospheric zenith path delay of GPS signal is divided into two parts, zenith hydrostatic delay (ZHD) and zenith wet delay (ZWD) [Iwabuchi et al. 2000].

Using the Sasstamoinen model [Davis et al. 1985] and surface pressure measurements $\left(\mathrm{P}_{0}\right)$ at GPS station, the ZHD can be calculated accurately through:

$$
Z H D=\frac{\left[(0.0022768 \pm 0.0000015) \mathrm{m}_{\mathrm{hPa}}{ }^{-1}\right] \mathrm{P}_{0}}{1-0.00265 \cos (2 \varphi)-0.000285 \mathrm{H}}
$$

where, $\varphi$ is the latitude and $H$ is the height from geoid in kilometers. The total zenith delay of the GPS signals is calculated during the processing of IPGN observations. By subtracting ZHD from the estimated total zenith delay, the ZWD is easily derived.

The ZWD is a function of the water vapor and atmospheric temperature. So, the PWV could be estimated when weighted average of the atmospheric temperature, $T_{m}$ is calculated. The PWV values are related to the ZWD as follows [Bevis et al. 1994]:

$$
\Pi=\frac{P W V=\Pi \times Z W D}{\rho_{\mathrm{w}} \mathrm{R}_{\mathrm{v}}\left[\left(\mathrm{k}_{\mathrm{b}} / \mathrm{T}_{\mathrm{m}}\right)+\mathrm{k}_{2}+\mathrm{k}_{1}\left(\mathrm{M}_{\mathrm{w}} / \mathrm{M}_{\mathrm{d}}\right)\right]}
$$

where, $\mathrm{M}_{\mathrm{w}}\left(18.0152^{\mathrm{gr}} / \mathrm{mol}\right)$ and $\mathrm{M}_{\mathrm{d}}\left(28.9644^{\mathrm{gr}} / \mathrm{mol}\right)$ are the molar masses of water vapor and dry air, respectively. The physical constants $\mathrm{k}_{1}\left(77.689^{\mathrm{K}} / \mathrm{hPa}\right), \mathrm{k}_{2}\left(71.295^{\mathrm{K}} / \mathrm{hPa}\right)$ and $\mathrm{k}_{3}\left(375463 \mathrm{~K}^{2} / \mathrm{hPa}\right)$ belong to the formula for atmospheric refractivity [Rüeger 2002].

\section{Numerical experiments and model configuration}

\subsection{Description of the model}

For each rainfall case, three numerical experiments are conducted. The initial and boundary conditions of the first experiment (CTRL) are prepared from the $\mathrm{Na}$ tional Center for Environmental Prediction (NCEP) global forecast system (GFS) analysis data. These data are used at a spatial horizontal resolution of $0.5^{\circ} \times 0.5^{\circ}$ and a time resolution of $3 \mathrm{~h}$. In the second experiment (CONVDA), using 3DVAR data assimilation system, the conventional surface and radiosonde observations are assimilated to generate model initial and boundary conditions. The third experiment (GPSCONVDA) is similar to the second one, but the GPS PWV measurements from the IPGN network are also assimilated into the WRF model. In each case, the model is integrated 54 hours ahead starting from the initial time at 1200 UTC one day before the rainfall event chosen.

The configuration of model includes 41 vertical layers and two nested domains. The grids spacing of 


\begin{tabular}{rrl} 
& Non-hydrostatic & Dynamics \\
& 41 vertical levels & Vertical resolution \\
Domain $2: 7 \mathrm{~km}$ & Domain 1: $21 \mathrm{~km}$ & Horizontal resolution \\
$42.63^{\circ} \mathrm{E}-61.82^{\circ} \mathrm{E}$ & $32.54^{\circ} \mathrm{E}-63.94^{\circ} \mathrm{E}$ & \\
$33.06^{\circ} \mathrm{N}-39.44^{\circ} \mathrm{N}$ & $18.69^{\circ} \mathrm{N}-42.45^{\circ} \mathrm{N}$ & Domains of integration \\
$(241 \times 97$ grids $)$ & $(142 \times 130$ grids $)$ & \\
WSM 3-class simple ice scheme [Hong et al. 2004] & Microphysic \\
RRTM scheme [Mlawer et al. 1997] & Longwave radiation option \\
Dudhia scheme [Dudhia 1989] & Shortwave radiation option \\
MM5 Monin-Obukhov scheme [Monin and Obukhov 1954] & Surface-layer option \\
Unified Noah land-surface model [Chen and Dudhia 2001] & Land-surface option \\
YSU scheme [Hong et al. 2006] & Boundary-layer option \\
Kain-Fritsch (new Eta) scheme [Kain 2004] & Cumulus option \\
\hline
\end{tabular}

Table 1. Details of domains and physics used in the model.

the inner and of the outer domains are 7 and $21 \mathrm{~km}$, respectively. The other details of domains and physical settings of the model are presented in Table 1.

\subsection{Assimilation methodology}

To ingest and assimilate the observational data into the WRF model, we utilized 3DVAR data assimilation technique [Barker et al. 2004]. This method provides the optimal estimate of the true atmospheric state via the minimization of the following cost function [Ide et al. 1997]:

$$
\begin{aligned}
J(x)=J^{b}+J^{o}=\frac{1}{2}\left(x-x^{b}\right)^{T} B^{-1}\left(x-x^{b}\right)+ \\
+\frac{1}{2}\left(y-y^{o}\right)^{T} O^{-1}\left(y-y^{o}\right)
\end{aligned}
$$

where, $x, x^{b}$ and $y^{o}$ are the vectors of analysis variable, background forecast and observation, respectively. $B$ is the background error covariance matrix and $O$ is the covariance matrix of the observational error.

In the WRF data assimilation system, the background error covariance matrix $B$ is calculated using the National Meteorological Center (NMC) method [Parish and Derber 1992], which uses the WRF forecasts differences with different ranges and valid at the same time. In this work, the differences of $12 \mathrm{~h}$ and $24 \mathrm{~h}$ WRF model forecasts were used and the background error statistics were made with one month forecasts in January 2014 for the domains.

The analysis control variables in WRF 3DVAR system are the amplitudes of empirical orthogonal functions (EOFs) of stream function, pseudo relative humidity, unbalanced part of temperature, velocity potential and surface pressure [Barker et al. 2004]. PWV is not a state parameter and the observation operator transforms the model control variables into the PWV counter-parts at the time and location of the observations. The observation operator of the GPS PWV which was used in the WRF 3DVAR system is expressed as follows [Iwabuchi et al. 2005]:

$$
P W V=\sum_{k=1}^{k=n k} \rho_{k} q_{k} d z_{k}
$$

where, $\rho\left(\mathrm{kg} / \mathrm{m}^{3}\right)$ is the air density, $q(\mathrm{~kg} / \mathrm{kg})$ is specific humidity and $d z(\mathrm{~m})$ is the height of the vertical model grid.

The two modes of performing the 3DVAR data assimilation are cold-start and cycling. In cold-start mode, 3DVAR generates the new background analysis only at the WRF starting time of forecast. In cycling mode, the forecasts of the WRF after a specific time window is used as a new background for assimilation instead of the background produced from GFS [Guo et al. 2004, Routray et al. 2010, Hsiao et al. 2012, Eiserloh 2014]. In this study, we use WRF 3DVAR data assimilation in cycling mode to account for the spin-up time of the forecasts. So, the forecasts of the WRF are used as a first guess for subsequent cycles with the $3 \mathrm{~h}$ time window. The structure of the 3 hourly cycling update is depicted in Figure 2. As it can be seen in Figure 2, before the start of the forecast (at 12 UTC) the assimilation is done three times. In other words, the assimilation spin-up time takes 6 hours.

\section{Numerical results}

In this section, the 3DVAR data assimilation technique in cycling mode is used to evaluate the impact of the observations on the WRF model simulation in precipitation, PWV and vertical relative humidity fields. 


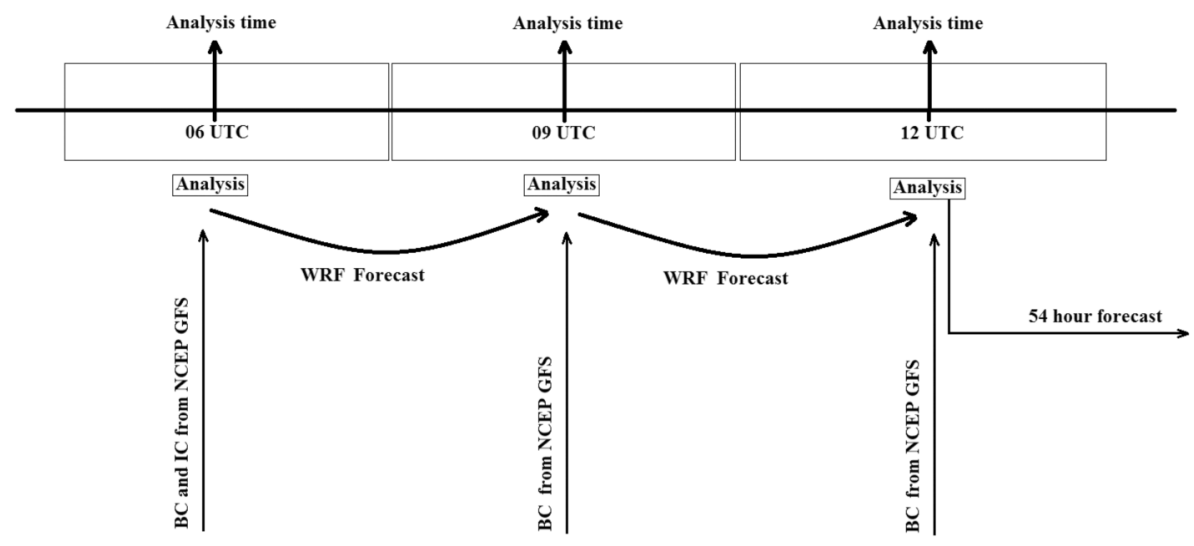

Figure 2. The structure of cycling 3DVAR data assimilation with $3 \mathrm{~h}$ time windows.

\begin{tabular}{cccc}
\hline Forecast day & CTRL & CONVDA & GPSCONVDA \\
\hline Day-1 & 4.03 & 3.81 & 3.78 \\
Day-2 & 3.02 & 2.91 & 2.97 \\
\hline
\end{tabular}

Table 2. MAE of the 24-hour accumulated precipitation (in $\mathrm{mm}$ ) simulated in different experiments. The WRF initialized at 12UTC, January 31, 2014.

Using the three numerical experiments introduced in Section 3.1, the simulations are conducted for the two rainfall cases previously introduced.

\subsection{Rainfall}

To evaluate the WRF model forecasts of precipitation in each experiment, we used observations of rain gauges in the study area. The mean absolute errors (MAEs) of the accumulated precipitation in $24 \mathrm{~h}$ simulations (day-1 and day-2) initialized at 12UTC, January 31, 2014 (Case-1) are given in Table 2. As it can be seen,

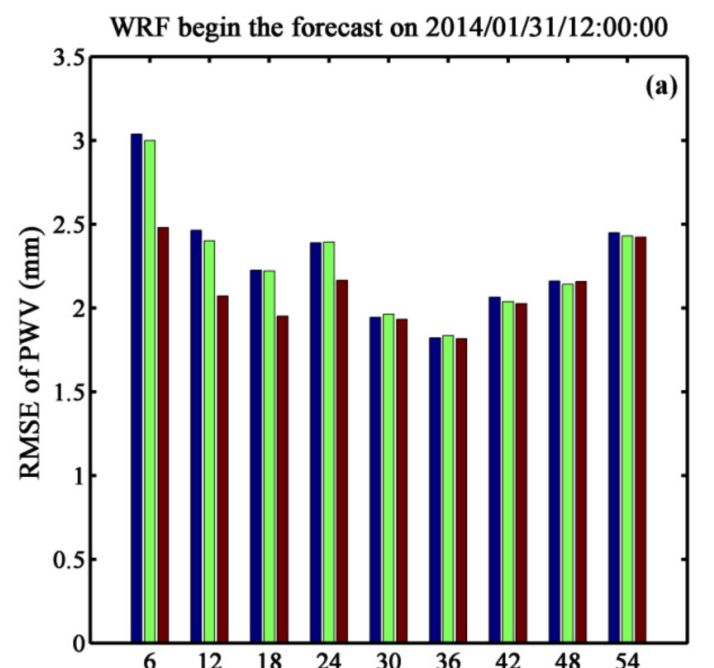

\begin{tabular}{cccc}
\hline Forecast day & CTRL & CONVDA & GPSCONVDA \\
\hline Day-1 & 2.9 & 2.52 & 2.41 \\
Day-2 & 1.74 & 1.41 & 1.53 \\
\hline
\end{tabular}

Table 3. MAE of the $24 \mathrm{~h}$ accumulated precipitation (in $\mathrm{mm}$ ) simulated in different experiments. The WRF initialized at 12UTC, September 16, 2014.

in day- 1 the inclusion of conventional data into the WRF model in the CONVDA experiment caused a 5 percent reduction in the accumulated precipitation forecast error as compared with the CTRL. The positive impact of data assimilation on the precipitation forecasts declined in day-2. The MAE values in Case- 1 show that there is no significant difference between CONVDA and GPSCONVDA simulated precipitations. So, the assimilation of GPS PWV measurements into the model has almost no effect on the accumulated precipitation forecast in Case-1.

WRF begin the forecast on 2014/01/31/12:00:00

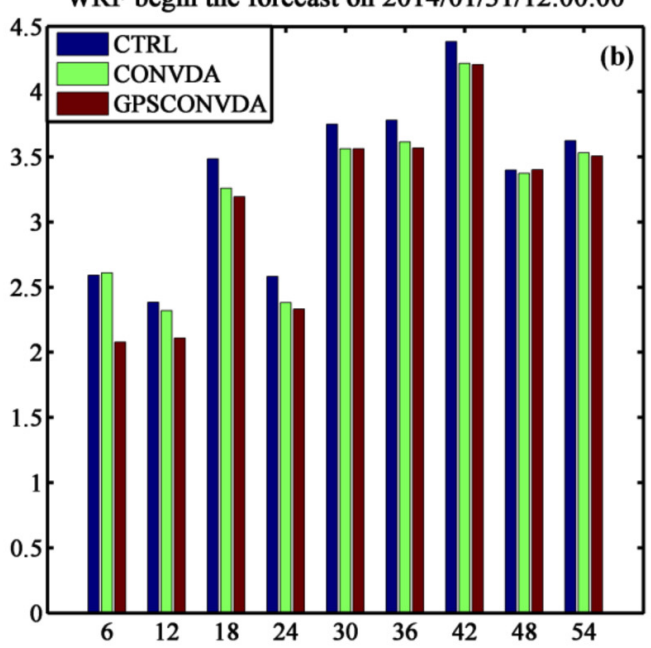

Figure 3. Six hourly RMSEs in predicted PWV using different experiments: CTRL, CONVDA and GPSCONVDA from the WRF forecast initialization in both case studies (a) February 1, 2014 and (b) September 17, 2014. 
Similarly, the MAE values of accumulated rainfall in 24h simulations (day-1 and day-2) initialized at 12UTC, September 16, 2014 (Case-2) are given in Table 3. According to the error values in this rainfall case, the data assimilation reduces the error on the first day of precipitation forecast. The comparison of the three experiments forecast errors shows that assimilation of observational data in CONVDA and GPSCONVDA experiments reduced the accumulative precipitation errors in day- 1 up to 13 and 17 percent respectively as compared to the CTRL. Therefore, the inclusion of PWV measurements obtained from IPGN stations into assimilation cycles decreases the rainfall simulation error of day-1 up to 4 percent. Also, the positive impact of conventional and non-conventional data assimilation is declined on the second day of the forecast.

\subsection{Precipitable water vapor}

The simulated PWV values from different experiments during the two rainfall cases are evaluated in this section. For this purpose, the estimated PWV values prepared from the IPGN GPS (using Equation (2)) stations located in the inner domain of the model are considered as reference and used to verify the corresponding simulated values of PWV in CTRL, CONVDA and GPSCONVDA experiments. Figure 3 shows the six hourly root mean squares error (RMSE) of the PWV obtained from the experiments in Case-1 (Figure 3a) and Case-2 (Figure 3a). The RMSE values have been calculated for all of the GPS stations located in the study area and are shown for different forecast lengths in this figure.
For each case study, GPSCONVDA and CTRL experiment simulated PWV have the minimum and maximum RMSE over the forecast length, respectively. The assimilation of conventional surface observations in comparison with the CTRL has almost no positive effect on PWV simulation in Case- 1 while in Case- 2 after $12 \mathrm{~h}$ from the start of WRF forecast, the CONVDA reduced the forecast error up to $0.2 \mathrm{~mm}$. The superiority of GPSCONVDA with respect to the CONVDA is clear in the first $24 \mathrm{~h}$ and $12 \mathrm{~h}$ forecast lengths of Case- 1 and Case-2, respectively. As it can be seen in Figure 3, it is found that the GPSCONVDA has reduced the PWV simulation error from 0.2 to $0.7 \mathrm{~mm}$. In other words, during the first $12 \mathrm{~h}$ and $24 \mathrm{~h}$ forecast lengths the assimilation of GPS observations improved the PWV prediction RMSE between 8 to 22 percent.

\subsection{Vertical relative humidity}

It is also important to validate the simulated vertical structure of relative humidity in both rainfall cases. The relative humidity prediction of three different experiments in vertical pressure levels is compared with the available corresponding radiosonde observations at Tehran Mehrabad airport (latitude $=35.68^{\circ} \mathrm{N}$, longitude $=51.35^{\circ} \mathrm{E}$ ). The $12 \mathrm{~h}$ and $24 \mathrm{~h}$ simulated relative humidity profiles together with the verifying observations (black graphs) are depicted in Figures 4 and 5 for the two cases, respectively.

The results of the model run starting at 12UTC January 31, for relative humidity profiles valid at 00UTC (Figure 4a) and 12UTC (Figure 4b) February 1 indicate
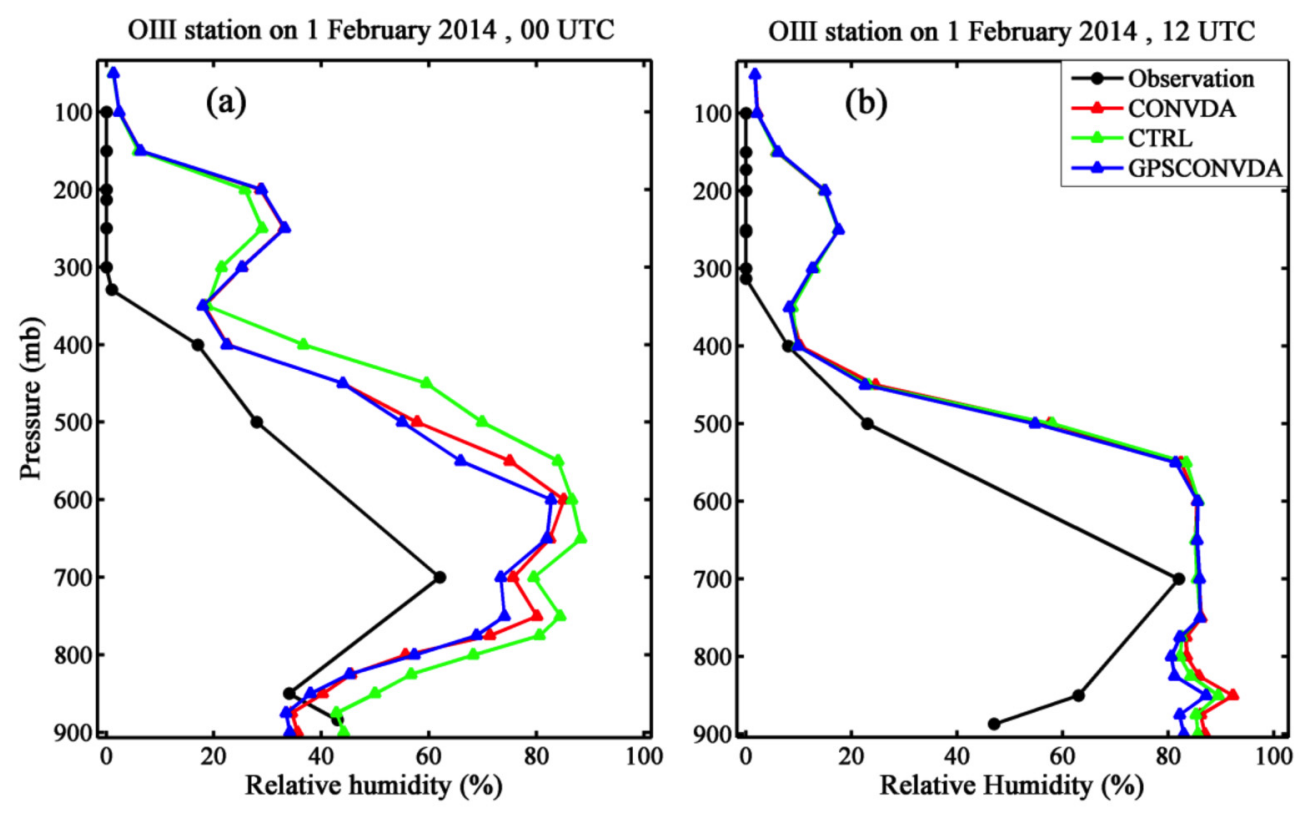

Figure 4. Comparison of the WRF predicted vertical profiles of relative humidity (\%) from different experiments with radiosonde observations at Tehran Mehrabad airport (OIII: latitude $=35.68^{\circ} \mathrm{N}$, longitude $=51.35^{\circ} \mathrm{E}$ ) in (a) $12 \mathrm{~h}$ and (b) $24 \mathrm{~h}$ simulation. The WRF start the prediction on January 31, 2014, 12 UTC. 

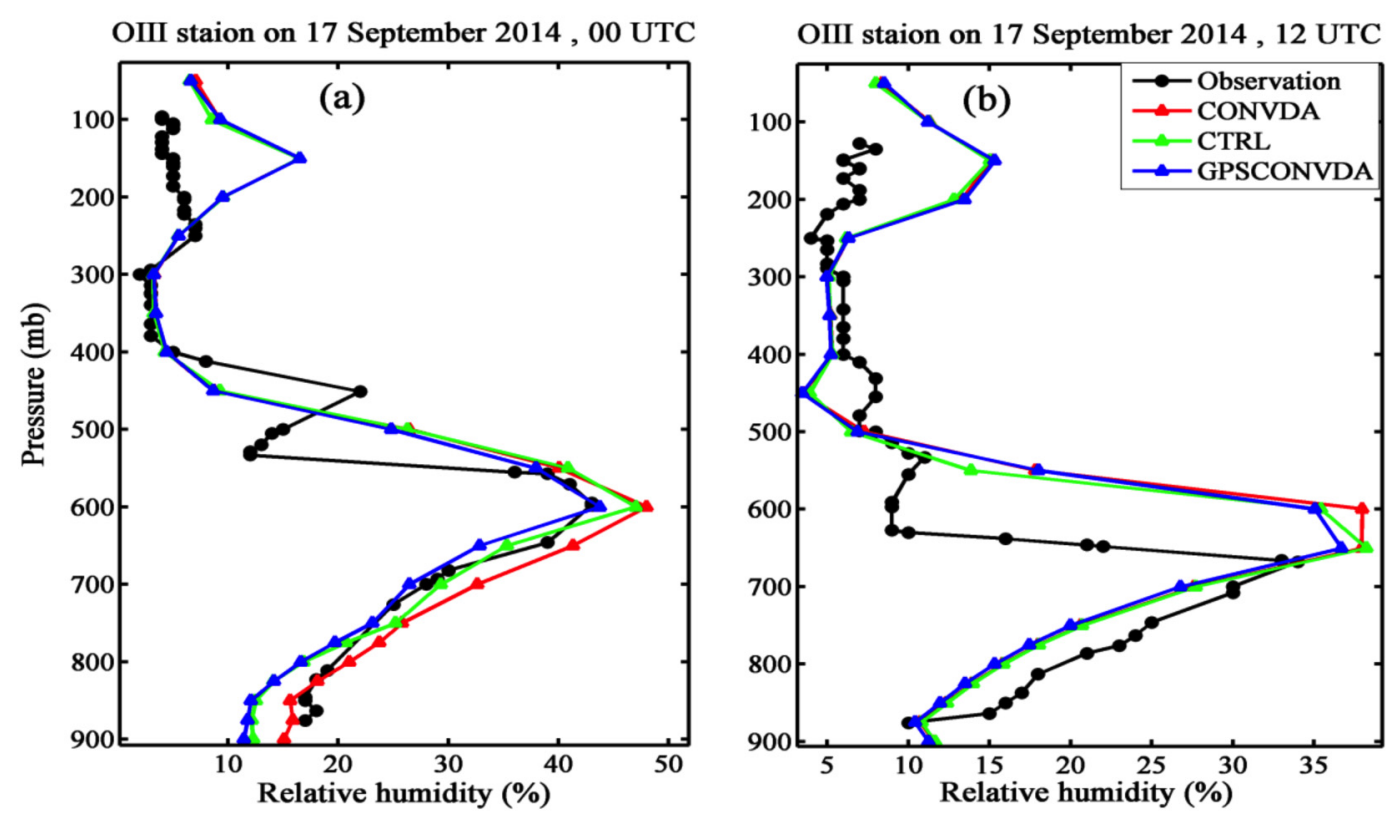

Figure 5. Comparison of the WRF predicted vertical profiles of relative humidity (\%) from different experiments with radiosonde observations at Tehran Mehrabad airport (OIII: latitude $=35.68^{\circ} \mathrm{N}$, longitude $=51.35^{\circ} \mathrm{E}$ ) in (a) $12 \mathrm{~h}$ and (b) $24 \mathrm{~h}$ simulation. The WRF start the prediction on September 16, 2014, 12 UTC.

that in the first $12 \mathrm{~h}$ the simulated vertical structure of moisture from the CONVDA (red graph) and GPSCONVDA (blue graph) experiments are slightly closer to the verifying observations as compared to the experiment without assimilation. In Case-2, the predicted $12 \mathrm{~h}$ relative humidity profiles from GPSCONVDA and CTRL experiments (blue and green graphs in Figure 5a) are fairly closer to the observations. Moreover, for the $24 \mathrm{~h}$ simulation of vertical relative humidity in both cases, there is no significant difference in the results of the three experiments.

From Figures 4a and 5a, it is seen that in general, GPS PWV assimilation may slightly modify the humidity values only in the lower levels without really touching the vertical structure. Even though there is a change in the structure, it is mostly ascribable to the vertical structure of background error covariances. Errors of the background are necessary to give an appropriate weight of contribution to the observations and background during analysis estimation [Bölöni and Horvath 2010]. Background error covariance (BE) of the WRF data assimilation system is in Eigen space but this information could be used to extract the BE in physical space [Barker et al. 2004]. We use single observation test on the model levels and extract the vertical profile of humidity background error standard deviation at radiosonde location. Figure 6 shows the structure of specific humidity background error standard deviation in the vertical model levels. As seen from Figure 6, the background error standard deviation of humidity decreases from surface to upper levels. It is thus expected that the incorporation of the observations should have the largest impact in the lower levels.
According to Figures $4 \mathrm{a}$ and $5 \mathrm{a}$, the three numerical experiments have resulted similar results in terms of relative humidity in the upper levels. The inclusion of the observations of conventional and GPS PWV data is more effective in the lower levels below $500 \mathrm{hPa}$. This could be probably attributed to the higher values of background standard deviation in lower levels (Figure 6).

\section{Conclusions}

In this study, 3DVAR data assimilation scheme for the WRF mesoscale model with two domains at 21 and $7 \mathrm{~km}$ horizontal resolutions were used to examine the impact of conventional (surface and radiosonde) observations and GPS PWV measurements as non-conventional observations in the simulation of precipitation, relative humidity and PWV over north of Iran. Using three sets of experiments, the simulations were performed for two rainfall events (February 1, 2014, and September 17,2014$)$ in the study area. The first experiment named as CTRL run without data assimilation. The other two experiments CONVDA and GPSCONVDA use 3DVAR data assimilation of conventional and GPS PWV along with the conventional observations, respectively.

We investigate the impact of inclusion of observational data using the 3DVAR scheme with respect to the GFS analysis data in generating the initial and boundary conditions used in WRF forecasts. Generally, comparison of the model results with the IRIMO observations indicate a better agreement of the simulations with CONVDA and GPSCONVDA experiments compared with the CTRL simulation as many studies reported earlier [Falvey and Beavan 2002, Leiming et al. 2012]. 


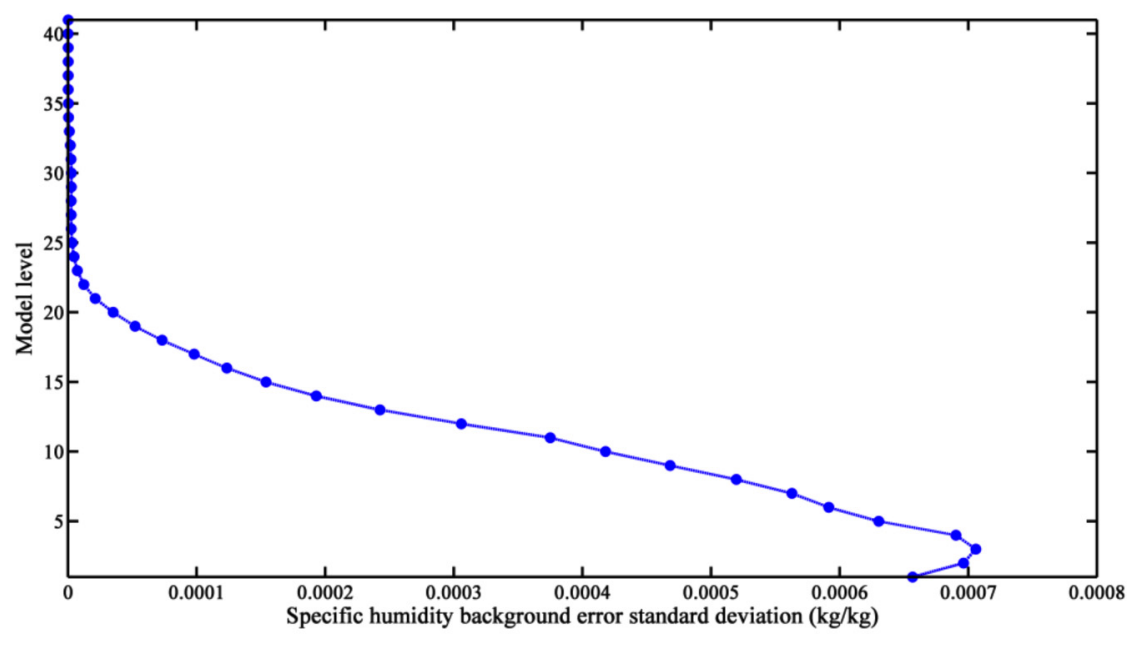

Figure 6. Vertical profile of specific humidity background error standard deviation at Tehran Mehrabad airport station. The profile is obtained from WRF 3DVAR single observation test in model levels.

In both rainfall case studies, inclusion of observation into the model improved the predicted cumulative precipitation on the first day of the forecast while the positive impact of data assimilation declines on the second day. Based on the results in Case-1 and Case-2 using assimilation of conventional observations, the MAE of the accumulated precipitation forecast in day- 1 reduced up to 5 and 13 percent, respectively. Also, the use of GPS PWV measurements together with conventional data reduced the rainfall simulation error up to 17 percent in the first forecast day of Case-2.

A comparison of simulated PWV values using different numerical experiments with corresponding values that were estimated from GPS observations showed that forecasts without data assimilation in CTRL experiment led to more errors in prediction compared with the CONVDA and GPSCONVDA experiments. Based on the result, the assimilation of GPS data reduced the RMSE of simulated PWV between 8 to 22 percent during the first $24 \mathrm{~h}$ of the forecast length.

To evaluate the effect of assimilation of observations on the prediction of vertical structure of relative humidity, the profiles of $12 \mathrm{~h}$ and $24 \mathrm{~h}$ simulated relative humidity were compared with the corresponding radiosonde observations at Tehran Mehrabad station. The $12 \mathrm{~h}$ simulations of relative humidity from the GPSCONVDA experiment which used 3DVAR system were slightly closer to the observations only in the lower levels compared to the CTRL experiment. In general, the results showed slightly more improvement at lower levels compared to higher levels. The reason for this is in agreement with higher values of background error variances for humidity at lower levels.

Overall, this study showed a positive impact on local simulations of the precipitation and PWV using surface, radiosonde and GPS observations in the 3DVAR data assimilation system. It should be noted that using a more sophisticated method of 4DVAR may improve the result further. The main reason for this is that the GPS data have high temporal resolutions and have to be used in their own time.

\section{References}

Barker, D.M., W. Huang, Y.R. Guo and Q. Xiao (2004). A three dimensional variational (3DVAR) system with MM5: implementation and initial results, Monthly Weather Review, 132, 897-914.

Bauer, H.S., V. Wulfmeyer, T. Schwitalla, F. Zus and M. Grzeschik (2011). Operational assimilation of GPS slant path delay measurements into the MM5 4DVAR system, Tellus A, 63 (2), 263-282; doi:10.111 $1 /$ j.1600-0870.2010.00489.x.

Bevis, M., S. Businger, T.A. Herring, C. Rocken, R.A. Anthes and R.H. Ware (1992). GPS meteorology: remote sensing of the atmospheric water vapor using the global positioning system, Journal of Geophysical Research, 97 (D14), 15787-15801.

Bevis, M., S. Chiswell, T.A. Herring, R.A. Anthes, C. Rocken and R.H. Ware (1994). GPS meteorology: mapping zenith wet delays onto precipitable water, Journal of Applied Meteorology, 33, 379-386.

Bölöni, G., and K. Horvath (2010). Diagnosis and tuning of background error statistics in a variational data assimilation system, Quarterly Journal of the Hungarian Meteorological Service, 114 (1-2), 1-19.

Chen, F., and J. Dudhia (2001). Coupling an advanced land surface-hydrology model with the Penn StateNCAR MM5 Modeling System. II: preliminary model validation, Monthly Weather Review, 129, 587-604.

Davis, J.L., T.A. Herring, I.I. Shapiro, A.E.E. Rogers and G. Elgered (1985). Geodesy by radio interferome- 
try: Effects of atmospheric modeling errors on estimates of baseline length, Radio Science, 20 (6), 1593-1607.

Duan, J.P., M. Bevis, P. Fang et al. (1996). GPS meteorology: Direct estimation of the absolute value of precipitable water, Journal of Applied Meteorology, 35, 830-838.

Dudhia, J. (1989). Numerical study of convection observed during the winter monsoon experiment using a mesoscale two-dimensional model, Journal of Atmospheric Sciences, 46, 3077-3107.

Eiserloh, A.J. (2014). WRF-Model Data Assimilation Studies of Land falling Atmospheric Rivers and Orographic Precipitation Over Northern California, Master's Theses, Paper 4461.

Falvey, M., and J. Beavan (2002). The impact of GPS precipitable water assimilation on mesoscale model retrievals of orographic rainfall during SALPEX'96, Monthly Weather Review, 130, 2874-2888.

Govindankutty, M., and A. Chandrasekar (2011). Impact of assimilation of ATOVS temperature and humidity and SSM/I total precipitable water on the simulation of a monsoon depression, Natural Hazards, 59, 1647-1669; doi:10.1007/s11069-011-9857-x.

Guo, Y.R., H. Kusaka, D.M. Barker, Y.H. Kuo and A. Crook (2004). Assimilation of ground-based GPS PWV with 3DVAR system for a IHOP case, In: Proc. of 20th conference on weather analysis and forecast/ 16th conference on numerical weather prediction, January 11-15, Seattle, WA, P1.13.

Hong, S.Y., J. Dudhia and S.H. Chen (2004). A revised approach to ice microphysical processes for the bulk parameterization of clouds and precipitation, Monthly Weather Review, 132, 103-120.

Hong, S.Y., Y. Noh and J. Dudhia (2006). A new vertical diffusion package with an explicit treatment of entrainment processes, Monthly Weather Review, 134, 2318-2341.

Hsiao, L.F., D.S. Chen, Y.H. Kuo, Y.R. Guo, T.C. Yeh, J.S. Hong, C.T. Fong and C.S. Lee (2012). Application of WRF 3DVAR to operational typhoon prediction in Taiwan: Impact of outer loop and partial cycling approaches, Weather and Forecasting, 27, 1249-1263.

Ide, K., P. Courtier, M. Ghil and A.C. Lorenc (1997). Unified notation for data assimilation: operational, sequential and variational, Journal of the Meteorological Society of Japan, 75, 181-189.

Iwabuchi, T., I. Naito and N. Mannoji (2000). A comparison of Global Positioning System retrieved precipitable water vapor with the numerical weather prediction analysis data over the Japanese Islands, Journal of Geophysical Research, 105 (D4), 4573-
4585; doi:10.1029/1999JD901007.

Iwabuchi, T., Y.R. Guo, C. Rocken, T. Van Hove and Y.H. Kuo (2005). Impact of Ground-based GPS retrievals on moisture field and rainfall forecast in WRF/3DVAR, WRF/MM5 Users' Workshop - June 2005 .

Kain, J.S. (2004). The Kain-Fritsch convective parameterization: An update, Journal of Applied Meteorology, 43, 170-181.

Kalnay, E. (2003). Atmospheric modeling, data assimilation and predictability, Cambridge University Press, Cambridge, $364 \mathrm{p}$.

Kuo, Y.H., Y.R. Guo and E.R. Westwater (1993). Assimilation of precipitable water measurements into a mesoscale numerical model, Monthly Weather Review, 121, 1215-1238; doi:http://dx.doi.org/10.11 75/1520-0493(1993)121<1215:AOPWMI>2.0.CO;2.

Kuo, Y.H., X. Zou and Y.R. Guo (1996). Variational assimilation of precipitable water using a nonhydrostatic mesoscale adjoint model. Part I: Moisture retrieval and sensitivity experiments, Monthly Weather Review, 124, 122-147; doi:http:/ / dx.doi.org / 10.1175/1520-0493(1996)124<0122:VAOPWU >2. $0 . \mathrm{CO} ; 2$.

Leiming, M., Q. Wuyun, F. Geng and G. Zhou (2012). Numerical weather prediction in Yangtze River Delta region with assimilation of AWS and GPS / PWV data, In: 2012 IEEE Symposium on Robotics and Applications (ISRA), 741-743; doi:10.1109/ISRA. 2012.6219297.

Lipton, A.E., G.D. Modica, S.T. Heckman and A.J. Jackson (1995). Satellite-model coupled analysis of convective potential in Florida with VAS water vapor and surface temperature data, Monthly Weather Review, 123, 3292-3304.

Mazany, A., S. Businger, S.I. Gutman and W. Roeder (2002). A lightning prediction index that utilizes GPS integrated precipitable water vapor, Weather Forecast, 17 (5), 1034-1047.

Mlawer, E.J., S.J. Taubman, P.D. Brown, M.J. Iacono and S.A. Clough (1997). Radiative transfer for inhomogeneous atmosphere: RRTM, a validated correlated$\mathrm{k}$ model for the longwave, Journal of Geophysical Research, 102 (D14), 16663-16682.

Monin, A.S., and A.M. Obukhov (1954). Basic laws of turbulent mixing in the surface layer of the atmosphere, Contributions of the Geophysical Institute of the Slovak Academy of Sciences, 24 (151), 163-187.

Parish, D.F., and J.C. Derber (1992). The national meteorological center's spectral statistical interpolation analysis system, Monthly Weather Review, 120, 1747-1763.

Rocken, C., R. Ware, T. Van Hove, F. Solheim, C. Alber 
and J. Johnson (1993). Sensing Atmospheric Water Vapor with the Global Positioning System, Geophysical Research Letters., 20, 2631-2634.

Rocken, C., T. Van Hove and R. Ware (1997). Near realtime sensing of atmospheric water vapor, Geophysical Research Letters, 24, 3221-3224.

Routray, A., U.C. Mohanty, S.R.H. Rizvi, D. Niyogi, K.K. Osuri and D. Pradhan (2010). Impact of Doppler weather radar data on numerical forecast of Indian monsoon depressions, Quarterly Journal of the Royal Meteorological Society, 136 (652), 1836-1850.

Rüeger, J.M. (2002). Refractive index formula for radio waves. Integration of techniques and corrections to achieve accurate engineering, In: Proceedings of the XXII FIG Intional Congress ACSM/SPRS Annual Conference, Washington, DC, USA, 19-26.

Srinivas, C.V., V. Yesubabu, K.B.R.R. Hari Prasad, B. Venkatraman and S.S.V.S. Ramakrishna (2012). Numerical simulation of cyclonic storms FANOOS, NARGIS with assimilation of conventional and satellite observations using 3-DVAR, Natural Hazards, 63, 867-889; doi:10.1007/s11069-012-0194-5.

Yunck, T.P., C.H. Liu and R. Ware (2000). A history of GPS sounding. Terrestrial, Atmospheric and Oceanic Sciences, 11, 1-20.

Zapotocny, T.H., J.A. Jung, J.F. LeMarshall and R.E. Treadon (2007). A two season impact study of satellite and in situ data in the NCEP global data assimilation system, Weather Forecast, 22, 887-909.

Zhang, M., Y. Ni and F. Zhan (2007). Variational assimilation of GPS precipitable water vapor and hourly rainfall observations for a meso- $\beta$ scale heavy precipitation event during the 2002 Mei-Yu season, Advances in Atmospheric Sciences, 24, 509-526.

Zhang, C.L., Y.H. Kuo, L.J. Dai, Y.L. Chu, J. Braun, J.J. Zhang, Q.C. Li and M. Chen (2008). The Design and Application of Network of Ground-Based GPS Water Vapor Monitoring Stations to Improve Precipitation Prediction in the Greater Beijing Metropolitan Area, International Society for Photogrammetry and Remote Sensing, Beijinig, China.

\footnotetext{
* Corresponding author: Ali Sam Khaniani, School of Surveying and Geospatial Engineering, University College of Engineering, University of Tehran, Tehran, Iran; email: ali.sam@ut.ac.ir. 